\title{
OBJETOS MÍTICOS AMERICANOS: \\ LIVROS DOS POVOS TRADICIONAIS E \\ EXPERIÊNCIAS DE LEITURA DA AUTORIA INDÍGENA NO BRASIL
}

Cynthia de Cássia Santos Barra*

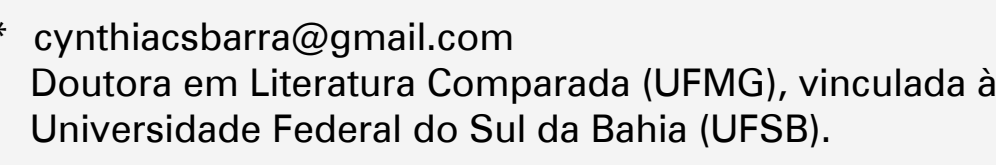

RESUMO: Este ensaio é, basicamente, resultado de um projeto de pesquisa realizado durante os quatro anos que trabalhei como de pesquisa realizado durante os quatro anos que trabalhei como professora na Universidade Federal de Rondônia. O projeto, intitulado de "Livros da Floresta: do registro etnográfico à criação literária" (Edital Universal CNPq/2011), permitiu-me orientar oito estudantes do Curso de Letras como bolsistas do Programa de Iniciação Científica daquela instituição, com planos de trabalhos voltados para as literaturas de autoria indígena produzidas pelos povos Maxakali, Suruí Paiter, Kaxinawá, Yanomami, Dessana, Pataxó e Cinta Larga. Neste ensaio, analisamos especificamenlos Dessana e pelos Maxakli, para, a patir desta experiénlos Dessana e pelos Maxakali, para, a partir desta experiência de leitura, problematizarmos as relaçoes entre mito e literatura e os alcances de nossos modos de ler a autoria indígena na contemporaneidade.

PALAVRAS-CHAVE: Autoria indígena; Experiência literária; Mito
RESUMEN: Este ensayo es básicamente el resultado de un proyecto de investigación llevado a cabo durante los cuatro años que trabajé como profesor de la Universidad Federal de Rondônia. EI proyecto, titulado "Libros de la Selva: de lo registro etnográfico a la creación literaria" (Edital Universal CNPq/ 2011), me permitió guiar a ocho estudiantes con formación en los estudios literarios, participantes de un Programa de Iniciación Científica de esa institución, con planes de trabajo dirigidos para la investigación de la autoría indígena de los pluebos indígenas Maxakali, Suru Paiter, Kaxinawá, Yanomami Dessana, Pataxó y Cinta larga. En Pater, Kaxina, Yanomami Dessana, Pataxó y Cinta larga. En pectivamente, por Ios Kaxinawá, Dessana Maxakali, par, respectivamente, por los Kaxinawá, Dessana y Maxakali, para, con base en esta experiencia de lectura, problematizar la relación en tre el mito y la literatura y el alcance de nuestras formas de leer la autoría indígena en la época contemporánea.

PALABRAS-CLAVE: Autoría indígena; Experiencia literaria; Mito. 
1. ALMEIDA; QUEIROZ. Na captura da voz, p. 261.

\section{BREVÍSSIMA INTRODUÇÃO: A TAREFA DESTE ENSAIO}

Lançar nosso olhar, nossa visada, para a miríade de objetos raros que frequentam o imaginário, as fabulações nacionais e pan-amazônicas, nossos discursos sobre o outro, sobre nossos mitos fundantes, sobre nós mesmos, sobre os mitos dos outros; realizar o gesto de decuplicar o olhar com o objetivo de fazer tensionar nossas teorias, caminhar em direção aos limites da racionalidade ocidental e seus métodos escrutinadores e/ou inventivos: esta é a tarefa deste ensaio.

\section{LIVROS DA FLORESTA}

As histórias de antigamente estão na base da literatura indígena e, como princípio, sustentam o pensamento nas suas várias sociedades, constituindo o que se poderia identificar como o espírito dessas civilizações. Mesmo a historiografia indígena, que, nos últimos anos graças à conquista da escrita, passou a existir, encontra seu fundamento na palavra dos antepassados - como dizem os indios - [os antepassados] são seus livros mais preciosos.

Rememorações. Em outubro de 2012, aconteceu, em Porto Seguro-BA, um encontro de pesquisadores sobre Leitura e Escrita em Sociedades Indígenas, o IX ELESI. Para a ocasião, escrevi um trabalho intitulado "Literatura de autoria indígena e revitalização das línguas indígenas” (BARRA, 2014) Retomo, a seguir, passo a passo, fragmentos desse texto, aos quais ajunto outros. Recortes de fontes e de argumentos que nos ajudarão a abrir caminho, ao longo desta seção 1 .

Sabe-se, em território brasileiro, a ação colonizadora foi realizada com extrema violência, visando o apagamento da cultura e, em alguns números casos, a extinção da vida de povos indígenas inteiros. Nesse contexto hostil, e com a Lei pombalina para a unificação linguística, essa determinação de substituição do nheengatu pelo português como língua oficial (Diretório dos Índios, 1755/1757), teve lugar o (quase) desaparecimento da autoria indígena, que só re-emergiria, como presença no campo editorial brasileiro, no final da década de setenta do século XX, com a publicação de "Antes o mundo não existia'(1980). Ressaltemos, a figura do autor indígena, já inaugurada na América Latina no período colonial por meio da ação de escritores e tipógrafos Guarani, precisou de quase dois séculos de incessante resistência para se fazer sentir como presença viva - e irredutível - no cenário intelectual, político e cultural do Brasil República.

Entre os mais de 500 livros de autoria indígena publicados nas últimas décadas, gostaria de comentar aqui, de modo breve, processos de produção e projetos editoriais de três deles. No horizonte de leitura desses livros, certamente publicados impulsionados por Programas e Ações afirmativas para a garantia de Direitos Constitucionais dos Povos Indígenas no Brasil, tais como a Educação Escolar Indígena 
e a Lei $11.645 / 08$, uma pergunta parece ter vindo para ficar: na contemporaneidade, muitos, começando a ser numerosos, são os livros de autoria indígena que nos ensinam sobre os modos de viver e as artes de ler e escrever dos povos indígenas quando outrora eram tão só viajantes, missionários, linguistas e antropólogos aqueles que se destinavam a tal tarefa? Tendo a pensar que alguns dos livros de autoria indígena que tenho lido nos últimos anos nos ensinam a ver um fato muito preciso (precioso talvez) e bastante paradoxal eles ensinam que ainda não sabemos ler os povos indígenas em sua irredutível alteridade.

Tentemos dizer como isso se dá, nesta e na próxima seção, perquirindo uma experiência de leitura profundamente vinculada ao campo do literário: o aprender a ler o que não se sabe - o que não se deixa - escrever/ ler, a não ser como uma experiência radical de alteridade.

O primeiro dos livros que gostaria de comentar é Shenipabu Miyui: histórias dos antigos (1995; 2000; 2008), de autoria dos professores indígenas Kaxinawá. Resultante da "experiência de autoria”, coordenada pela Comissão Pró-Índio do Acre (CPI-AC), teve sua primeira publicação em 1995, com selo editorial da própria CPI-AC, sendo reformulado graficamente e reeditado em 2000, com nova tiragem em 2008 pela Editora Universitária da UFMG. Vale sublinhar que, até finais do século XIX, os Kaxinawá eram uma sociedade de tradição predominantemente oral. Conforme Nietta Lindenberg Monte, "as escritas alfabética e numérica, desconhecidas dos Kaxinawá até a vigência da empresa seringalista, foram objeto de interesse desde inícios do século XX percebidas como um importante instrumento da dominação socioeconômica sobre eles exercida. ${ }^{2}$ Em seu relato sobre "O Livro e sua Construção”, Monte assevera que tão importante quanto o resultado "histórico, linguístico e estético do livro Shenipabu Miyui (...) é contarmos aqui o processo educativo de sua elaboração coletiva pelos Kaxinawá”. ${ }^{3}$

Escutemos, pois, um pouco dessa história e seus desdobramentos. Os professores Kaxinawá realizaram uma pesquisa que durou seis anos, durante os quais os jovens pesquisadores gravaram as falas dos mais velhos, mestres da tradição, "muitas horas de trabalho foram consumidas de 1989 a 1995, na revisão linguística e no aprimoramento estilístico da obra" ${ }^{4}$ Por fim, era preciso decidir sobre a língua ou as línguas presentes no livro:

A presença no livro das versões em português das histórias dos antigos não foi uma decisão simples: num primeiro momento, os professores haviam decidido elaborar um livro só em Hãtxa Kuî. Visando o fortalecimento político e a valorização cultural da sua língua, sem coloca-la em relação, quase sempre desvantajosa, com a língua portuguesa. Após discussões e alguns trabalhosos anos de escrita em língua indígena, entenderam ser
2. MONTE apud KAXINAWÁ. Shenipabu Miyui, p. 14.

3. MONTE apud KAXINAWÁ Shenipabu Miyui, p. 16.

4. MONTE apud KAXINAWÁ. Shenipabu Miyui, p. 17. 
5. MONTE apud KAXINAWÁ. Shenipabu Miyui, p. 18-19.

6. ALMEIDA; QUEIROZ. Na captura da voz; BICALHO. Koxux, a imagem do Yàmiy na poética Maxakali. importante que os mitos pudesse chegar também às mãos das outras sociedades indígenas e dos leitores brasileiros em geral. (...) As versões em português das versões em Hãtxa Kuî foram posteriormente transcritas por professores Kaxinawá em Rio Branco e depois foram revisados sob minha assessoria, visando-se sua complexa passagem de língua oral em língua escrita.

Shenipabu Miyui: história dos antigos foi indicado como leitura obrigatória para o vestibular de duas universidades federais brasileiras (UFMG, 2001; UFVJM, 2011). Inscreveuse, assim, em um espaço institucional restrito às obras consideradas estruturantes do sistema literário brasileiro.

O segundo livro que gostaria de mencionar é Antes o mundo não existia (1980; 1995), dos autores Umúsin Panlõn Kumu e Tolamãn Kenhríri, da etnia Desana. Considerado por especialistas $^{6}$ como o primeiro livro de autoria indígena publicado em língua portuguesa. A primeira edição, de 1980, continha 239 páginas, tendo sido publicada pela Livraria Cultura Editora (São Paulo). Foi destinada ao público externo às aldeias, com introdução e notas da antropóloga Berta G. Ribeiro. Em 1995, a obra foi ampliada, passou a ter mitos não contemplados na primeira edição, reeditada, contendo 264 páginas, em parceria, pelo selo editorial da Federação das Organizações Indígenas do Rio Negro (FOIRN) e da União das Nações Indígenas do Rio Tiquié (UNIRT), tornando-se o ponto de partida de uma coleção (Coleção Narradores Indígenas do Rio Negro, volume
1), que pudesse acolher outras narrativas a serem escritas e colocassem em circulação, nos povoados indígenas, sobretudo entre os jovens estudantes nas escolas espalhadas por todo o noroeste do estado do Amazonas, as narrativas míticas contadas por Umúsin Panlõn Kumu (Firmiano Arantes Lana) a seu filho Tolamãn Kenhríri (Luiz Gomes Lana).

A princípio não pensei em escrever essas histórias. Foi quando vi que até rapazinhos de dezesseis anos, com o gravador, começaram a escrevê-las. Meu primo-irmão, Feliciano Lana, começou a fazer desenhos pegando a nossa tribo mesmo, mas misturados com outras. Aí falei com meu pai: "todo mundo vai pensar que a nossa história está errada, vai sair tudo atrapalhado”. Aí ele também pensou... Mas meu pai não queria dizer nada, nem para o padre Casemiro, que tentou várias vezes perguntar, mas ele dizia só besteiras assim por alto. Só a mim que ele ditou essas casas transformadoras. Ele ditava e eu escrevia, não tinha gravador, só tinha caderno que eu mesmo comprei. (...) Quando terminei, quando enchi todo um caderno, mandei o caderno para o padre Casemiro, o original em desana, a história da criação do mundo até a dos Diloá. Continuei trabalhando, fazendo outro original, já em português. Aí pedi ao padre Casemiro para publicar, porque essas folhas datilografadas acabariam se perdendo, um dia podiam ser queimadas, por isso pedi que fosse publicado para ficar no meio dos meus filhos, que ficasse para sempre.
7. Tolamãn Kenhríri apud Umúsin Panlõn Kumu; Tolamãn Kenhríri. Ates o mundo não existia, p. $11-12$ 
Em 2009, a Editora da Universidade Federal do Amazonas (EDUA), em parceria com o Museu Amazônico, lança a série "autores indígenas", com a publicação da obra A origem da noite $\&$ Como as mulheres roubaram as flautas sagradas, com ilustração e texto original em Desana, e autoria de Feliciano Pimentel Lana, primo de Tolamãn Kenhríri. Refletir sobre os caminhos da escrita e dos desdobramentos editoriais dessas publicações desana, é interessante, entre outras questões, porque nos permite ver com alguma clareza diferentes circuitos editoriais (e, certamente, circuitos mercadológicos) dos livros indígenas. Como assinalado, a primeira edição sa por uma editora privada paulista; a segunda, pelo selo editorial de duas organizações indígenas do Amazonas. A segund edição teve como principal objetivo possibilitar que o livro circulasse também entre os povoados indígenas, objetivo que não teria sido alcançado pela primeira edição. Além disso, a reedição vincula-se à inauguração de uma coleção intitulada "Narradores Indígenas do Rio Negro". Podemos pensar aqui em um processo de conquista da escrita caminhando tam bém na direção do domínio dos meios de produção editorial Isso é exemplar e bastante significativo quando colocamos no horizonte o desenvolvimento de estratégias para a autodeterminação dos povos indígenas.

O terceiro livro que gostaria de mencionar é Hitupmãax (2009). Em 2006, ao serem entrevistados durante a seleção para ingresso no Curso de Formação Intercultural para Educadores Indígenas da UFMG, os professores Rafael, Pinheiro e Isael Maxakali disseram: "queremos estudar na universidade para fazer um livro que ensine a FUNASA a trabalhar com a gente". ${ }^{8} \mathrm{O}$ desejo de escrever um livro para ensinar médicos, enfermeiras, agentes de saúde das diversas instituições que interagem com o povo Maxakali foi concretizado. O processo de pesquisa, elaboração de textos, edição e publicação durou quase três anos. No texto que apresenta o processo de produção do livro de saúde Maxakali, Vânia Baeta Andrade afirma:

Havia (e há) um desejo em causa: transmitir uma cultura, uma cosmovisão, na qual está incluída uma certa, preciosa, concepção de vida e de morte. Desejo de ensinar, sim, pois são professores. Ensinar a cuidar: cuidar da vida, cuidar da morte, cuidar do corpo-espírito na imensidão que o constitui. A equipe escutou e cuidou. Cuidou para que o livro pudesse ser escrito respeitando a esse princípio. ${ }^{9}$

Uma equipe multidisciplinar juntou-se aos professores Maxakali para compor o livro. Muitas horas de gravação de conversas, depoimentos, narrativas e cantos rituais Maxakali. As conversas e leituras realizadas eram provenientes de muitas áreas de conhecimento: psiquiatria, psicanálise, linguística, antropologia, enfermagem, clínica média
8. MAXAKALI. Hitupmã'ax, p. 11

9. BAETA apud MAXAKALI Hitupmã'ax, p. 246. 
10. ALMEIDA. Polichinelo, p. 61

11. ALMEIDA. Polichinelo, p. 62 geral, teoria literária. O material reunido, páginas e páginas de transcrição de conversas, configuraram "material heterogêneo quanto ao gênero, à língua (maxakali e português em vários registros e tons), à intenção, à intensidade das informações". ${ }^{10}$ O livro de saúde Maxakali concretizou-se por meio de uma proposta editorial inusitada. Tendo como referência a experiência literária da portuguesa Maria Gabriela Llansol e as teorizações sobre o livro americano (a lógica rizomática) em Gilles Deleuze, o material selecionado ao longo da pesquisa, traduzido e, obstinadamente, retraduzido, ganhou a forma de três colunas paralelas, compondo um livro que é, a uma só vez, no mínimo, três. Nas palavras de Almeida, coordenadora editorial do projeto:

Assim, dispostos na página como colunas sem fim, que podem ser lidas separadamente e/ou em possíveis relações horizontais, transversais e verticais, os três livros sempre podem se tornar mais do que três. A coluna de dentro é da Paisagem, a escrita pelos Maxakali; a do meio é a da Polimorfa Mulher, com as ambiguidades da conversa entre nós (aqui incluo os seis maxakalis participantes da experiência); a de fora, Microcosmos do Homem, com a terminologia médica tentando conceptualizar (cientificar?) o saber que a memória maxakali tem guardado misteriosamente, apesar da desgraça da colonização. ${ }^{11}$
O livro de saúde Maxakali, objeto cultural híbrido, sem categorização de gênero definível, não pertencendo exatamente à tradição literária ocidental, nem às compilações de mitologias ameríndias ou ao saber científico stricto sensu. Em março de 2009, menos de um ano após sua publicação, teve várias de suas páginas incorporadas a uma cartilha da FUNASA, passando, assim, a fazer parte das referências bibliográficas do Projeto VIGISUS II, um programa da Secretaria de Vigilância em Saúde, do Ministério da Saúde. Nesse caso específico, tendo como referência o caráter atual das relações interétnicas no Estado brasileiro contemporâneo, é relevante observar como a palavra escrita em livro, com seus caminhos e destinos imprevistos, faz a autoria Maxakali penetrar ativamente em um espaço sócio-político historicamente monopolizado pela linguagem científica e razão ocidentais.

Os três livros apresentados enfrentaram, para sua construção, cada um à sua maneira, problemas tradutórios - tradução intralingual, interlingual, intersemiótica -; e precisaram inventar seus métodos fronteiriços específicos; em todos os três, as formas de produção de conhecimento foram marcadas por práticas colaborativas e interculturais. Os três livros foram forjados em meio as tensões entre os sujeitos advindos de sociedades de tradição oral e os de tradição escrita: autores indígenas, assessores científicos - linguistas, educadores, antropólogos, médicos, psicanalistas, etc. Esses 
livros tornaram-se objetos mais ou menos poéticos; heteróclitos todos eles em suas composições; insólitos e estranhos em seus discursos e narrativas; poderiam também dialogar com a Literatura; se assim o quisermos. Todos os três livros carregam, pelo menos em algumas de suas páginas, histórias míticas e canto-poemas.

Não sem resistência, e talvez para escândalo de alguns, já fazem parte de listas canônicas de vestibulares de universidades federais; propiciaram a escritores indígenas assumi o lugar de editores; foram capazes de uma proeza bastante significativa - injetaram no discurso médico da FUNASA células míticas do discurso indígena como co-ordenadores de mundos outros e de procedimentos na área da saúde.

Não há dúvida, como fato pertinente à cena contemporânea, os livros de autoria indígenas penetraram o mundo da cultura impressa, inscreveram aí formas e estilos indígenas específicos. Hoje no Brasil podemos falar de obras de autoria maxakali, kaxinawá, dessana, pataxó hãhãhãe, xavante. São reais existentes, e tão desconhecidos ainda.

São objetos do nosso mundo urbano e do mundo da floresta. Ocupam vários espaços de sentido. Participam da composição da miríade de objetos culturais estranhos, in sólitos, fantásticos, objetos resistentes às nossas abstrações teóricas homogeneizadoras. Dialogam, de um modo ainda não pacificado, de um modo selvagem, talvez dissessem alguns; dialogam com diversas escolas estéticas, com variadas escolas teóricas, com concretas políticas editoriais.

\section{SEÇÃO 2. LER E RELER OS LIVROS DA FLORESTA}

$O$ que está por vir. Após quase dez anos lendo livros indígenas, penso que não sabemos o que são os livros de autoria indígena. Eles compõem um fabuloso campo de potência inventiva, creio. Comprender isso talvez seja um bom modo de nos relacionarmos com esses livros, enquanto persistimos na nossa tarefa de encontrar sentidos para as nossas práticas e métodos atuais de leitura dos livros de autoria indígena; e das compilações e antologias de mitos que chegaram até nós por meio de viajante, cronistas, folcloristas e etnólogos. Até onde podemos ir em nossas leituras?

Uma questão conceitual de fundo esteve presente na primeira parte de minha exposição, ainda que não a tenha explicitado, e diz respeito à questão comumente levantada quando se discute a produção escritural indígena na contemporaneidade: os textos criativos indígenas são literatura? As narrativas mitológicas indígenas podem/devem ser tomadas como Literatura? São, especificamente, Literatura Oral?

Antônio Risério, em Tribos e textos: poéticas extra-ocidentais nos trópicos (1993), é enfático: "Não há povo que não ostente, no elenco dos seus signos mais expressivos, objetos 
12. RISÉRIO. Textos e tribos, p. 25

13. BORGES. Oralidade e Literatura, p. 7. de linguagem, correspondentes ao que, em nosso mundo, chamamos poesia". ${ }^{2}$ Sem nós enroscarmos demasiado na questão espinhosa de pretender determinar se os textos criativos indígenas são ou não, de fato, Literatura Oral ou se apenas se tornam Literatura quando se inserem na Cultura do Impresso e encontram seus leitores, mas vale considerar que o fazer literário com povos indígenas - a prática da letra - tem funcionado como abertura, uma fissura no mundo, por meio da qual todo um novo espaço de invenção e de enunciação se afirma. As narrativas míticas fundam o espaço dialógico nos livros de autoria indígena e, aí, a partir daí falam os autores indígenas.

Sabemos, nas sociedades de tradição tribal/oral, o mito apresenta-se como uma estrutura complexa e multidimensional. Por meio do mito, se nos lançarmos sob a orientação teórico-metodológica da Análise do Discurso, isto é, se nos dedicarmos à investigação da discursividade do mito, podemos ter acesso às representações estabelecidas entre povo, território e história. "Como prática discursiva, o mito responde ao imaginário e à formação ideológica que, mediante mecanismos de ordem histórico-social, produzem efeitos de identidade". ${ }^{13}$ Conhecer melhor o contexto sócio-histórico de produção dos mitos para conhecer melhor os povos indígenas; conhecer melhor os povos indígenas para conhecer melhor as narrativas míticas: nossa via de mão dupla. Essa é nossa tarefa como leitores de literatura indígena?
Como caminhar nesse ainda novo, estranho, insólito, instável, espaço de leitura que se abre para nós ao adentrarmos no mundo conforme os mitos indígenas enunciam?

Como reagir a um mundo sem regras, que se apresenta como a mais pura anarquia? $\mathrm{Ou}$, ao contrário, tão determinado, que já não permita escolhas? Como passar de um para o outro, ou, melhor, quão desejável se torna saltar da anarquia para o jogo mais estrito? Estas são questões que podem acompanhar, como se verá, a leitura de um texto estranho, por exemplo, o mito da origem do fogo xavante, quando este cai nas mãos de um leitor desavisado. Essa perplexidade diante do estranho já foi exemplarmente apresentada, ao que me consta, em dois textos de ficção bem conhecidos, ambos assinados por Lewis Caroll: Alice no País das Maravilhas (1865) e Através do espelho (1871), sua sequência. Como bem resumiu num ensaio exemplar de 1962, o poeta inglês W.H. Auden: "No País das Maravilhas Alice tem de se adaptar à vida sem leis; no País do Espelho, à vida governada por leis com as quais não está familiarizada". Num caso, ela não reconhece as leis (pode ser que essas existam, num nível inconsciente), no outro ela não as aceita. Ora, parece-me que foram essas as alternativas com as quais eu próprio me deparei quando me pus a ler pela primeira vez os textos da literatura Xavante, no final da década de 1980, graças à antologia organizada por Bartolomeu Giaccaria e Adalberto Heide, em dois volumes, intitulados Jerônimo xavante canta e Jerônimo xavante sonha.. ${ }^{14}$ 
O leitor da literatura xavante mencionado na longa citação não sou eu, mas Sérgio Medeiros. Aprendi uma lição por meio da experiência de leitura de Medeiros. Recorro, então, a um ensaio de Medeiros, intitulado "Ainda não se pode ler em Xavante”, para avançarmos um pouco em nossa reflexão sobre a leitura dessa literatura/poética ameríndia, extraocidental, que a ele (e a mim também me) parece impossível de ser lida. A suposta impossibilidade de leitura, vocês verão, não nos afasta dos textos ameríndios, antes nos propicia a condição necessária para pensarmos nossos métodos para abrir caminhos em direção à textualidade performática dos mitos - e à sua alteridade radical.

A nossa condição, a condição da maior parte de nós de não falantes de línguas indígenas, cria inicialmente uma dificuldade de recepção da literatura ameríndia. No momento seguinte, com um texto já traduzido em mãos, um caos narrativo se apresenta ao leitor ocidental. Nas narrativas mitológicas, invariavelmente, multiplicam-se encontros sobrenaturais que obscurecem a descontinuidade entre natureza e cultura ("a onça é avô, o menino perdido é neto da onça"); há riqueza intrínseca das mitologias indígenas, com seu repertório de imagens e metamorfoses, desautoriza fluxos narrativos lineares; há a insistência na descrição de encontros sobrenaturais que embaralham todas as noções, e nos obrigam a repensar a descontinuidade entre o homem e os animais, trazendo à cena do pensamento a questão de "subjetividades não-humanas" (o que a princípio foi lido pela crítica literária como animismo ou antropomorfismo; e, depois, recebeu da antropologia outras chaves teóricas interpretativas - pensamento selvagem, perspectivismo, por exemplo).

É sempre possível tentar ordenar o caos, inventariar as recorrências, planificar os enredos. Não foi esse o método utilizado preferencialmente pelos estudos estruturalistas para ler os mitos indígenas? Tal método possibilitou a Medeiros, em sua tarefa impossível de ler a literatura xavante, o estabelecimento de algumas conclusões, que grosso modo, ele resume assim:

[...] alguém, digamos uma criança ou uma mulher, ou um adulto, estigmatizado por alguma razão, ou um velho, toso personagens marginalizados (porque estão vivendo à margem da sociedade viril, dos caçadores), afasta-se de casa e se aprofunda na florestal, onde dialoga com o outro, o extremamente outro, se pensarmos que, além dos animais, espíritos também podem cruzar o caminho desses índios solitários. Tem-se aî uma experiência vivida em condições anormais, de extrema solidão e desamparo. ${ }^{15}$

Maurice Blanchot, autor também tomado por Medeiros como uma referência importante para prosseguir em seu exercício de ler os Xavante, supõe que a literatura é, hoje e sempre foi, a afirmação de um discurso completamente outro. Penso 
que esteja nessa afirmação de Blanchot - a compreensão da literatura como lugar da experiência irredutível da alteridade - o ponto de articulação possível - o lugar de imbricação mais produtivo, em meu ponto de vista - entre o discurso mítico indígena imemorial e a autoria indígena contemporânea que se abriu para nós por meio dos Livros da Floresta.

O que está em jogo, a partir dessa compreensão, não exatamente os sentidos que serão fixados a partir da leitura realizada, ainda que a saibamos impossível por princípio afinal como ler o que nos é radicalmente outro? (nós não teríamos meios para tanto) - mas, o que está em jogo aqui, creio, é o próprio jogo de colocar em movimento nossa imaginação inventiva e nossa capacidade de produzir artefatos (livros, canções, filmes, desenhos) a partir do encontro com o outro, do radicalmente outro.

Não é uma questão de domínio, não é uma questão de conhecer para melhor dominar ou pacificar o outro. Antes, o desejo de um jogo incessante e inventivo com as diferenças e com as perdas históricas - as ruínas de nossa história cultural. Quanto a mim, como método de leitura, a esse jogo capaz de dar prosseguimento à impossível leitura dos textos ameríndios, eu o chamo, com o fez Sousândrade e Haroldo de Campos, eu o chamo de transcriar.

Lembro-me aqui de um exemplo de transcrição de uma canção tupinambá, com o qual gostaria de encerrar minha fala. Escutei-a por primeira vez cantada por Caetano Veloso, num álbum chamado "Noites do Norte". Depois soube que era uma canção musicada por Caetano a partir de um poema de Waly Salomão. Depois soube que o poema de Waly Salomão era uma transcriação a partir de registros etnográficos produzidos no período colonial e que terminaram sendo enxertados, como presença da voz indígena, num ensaio de Montaigne, escrito em 1878-79. Depois soube, por fim, que a canção talvez nunca tinha sido dos tupinambás, mas invenção provável da pena de Montaigne, após ele ter lido Jean de Léry e outros viajantes do período colonial.

A (imaginária) canção tupinambá de Waly soa assim nas "Noites do Norte" de Caetano:

Para de ondular, agora, cobra coral:

a fim de que eu copie as cores com que te adornas,

a fim de que eu faça um colar para dar à minha amada, a fim de que tua beleza

teu langor

tua elegância

reinem sobre as cobras não corais ${ }^{16}$

De todo modo, imaginemos nós aqui-agora um canto, provavelmente entoado em outro ritmo e melodia, cantado pelos Tupinambás do litoral que hoje chamamos de Rio de Janeiro, cantado num tempo que para nós soaria quase
16. SALOMÃO apud VELOSO. Noites do Norte, s.p. 
apenas feito de brumas e começos, o tempo anterior à chegada dos portugueses. Imaginemos um canto, uma canção de amor, um poema visual, talvez até mesmo uma canção sobre uma cobra coral ondulando, cantada em meio a canções de guerra e a cantos e louvores. Imaginemos, imaginemos, apenas isso nos resta - imaginar, fabular, transcriar; e a falsa canção tupinambá re-criada, essa que acabei de ler para vocês, ressoa ainda tão real como música nas Noites do Norte (2000)? A história dos textos ameríndios é uma história de silêncios, traições, equívocos de leitura, falseamentos - incertezas. Não duvidemos disso.

De todo modo, é sabido, parece certo que os cantores indígenas, assim como os guerreiros, gozavam de grande prestígio entre os seus e até entre as tribos inimigas de seu povo. (Fernão Cardim chega a dizer que os cantores não eram canibalizados quando caíam prisioneiros). Risério afirma:

No Tratado Descritivo do Brasil, em 1857, escrevendo sobre os tupinambás da velha Kirymuré, atual Bahia de Todos os Santos, Gabriel Soares de Souza emprega diversas vezes a expressão "grandes cantares" - e em todas estas vezes estamos diante da presença do texto na dança e na música. Pelo número e variedade de situações em que tais cantares aparecem, concluímos que era intensa a comparência da poemúsica na vida social tupinambá.
Para Antônio Risério, “[n]ão só os poetas precisam abrir os olhos e o coração para a poesia indígena (e africana), como os etnógrafos precisam nos mostrar mais sistematicamente a colheita poética de suas expedições" ${ }^{18}$ Isso porque assim que os textos trazidos a nós pelos etnógrafos fossem, por fim colocados na mesa, caberia ainda aos nossos poetas a tarefa de recriá-los "em linguagem esteticamente eficaz" .

A busca da recriação dos objetos signícos (narrativas míticas, canções de guerra, canções de amor, de louvor, cantos ritualísticos, discursos do cotidiano), re-criação via tradução linguística, intersemiótica, intercultural, a tradução e a atualização dos textos (verbais, sonoros, visuais) pelos próprios povos indígenas ou por poetas, como quer Risério, busca, tem como tarefa, a recriação desses artefatos em linguagem esteticamente eficaz. Mas, não apenas isso, sabemos. Estética e Política caminham juntos. Estar diante dos textos ameríndios, para nós, pertecentes à tradicão ocidental, como leitores ou re-criadores, é estar diante de um complexo epistêmico; é colocar-se diante dos limites mesmo de nossas formas de construir teorias sobre o outro e sobre o discurso do outro.

O que somos capazes de ler, então, nos livros de autoria indígena contemporâneos? Que eles existem, não param de existir como uma experiência de alteridade para nós. Que nós podemos lê-los, apesar de todas as impossiblidades, sempre 
caminhando entre inevitáveis-irredutíveis equívocos tradutórios e insistentes desencontros nos modos de viver e de pensar.

Assim, ao tempo que fazemos, por meio de nossa prática de leitura, as nossas escolhas estéticas e políticas, vamos inventando historicamente os nossos modos de relação com o outro, com o radicalmente outro. Não desejamos repetir o gesto dos colonizadores - conhecer para dominar; conhecer o outro apenas conforme os nossos valores nos permitem. Ter consciência disso me parece uma boa opção metodológica para aqueles que habitam espaços culturais de fronteira, mundos limítrofes; para aqueles que desejam ler literatura de autoria indígena. Não perder de vista, então, a miríade de objetos insólitos que cintilam diantes de nós, irredutivelmente insólitos e incomensuráveis.

\section{REFERÊNCIAS}

ALMEIDA, Maria Inês de; QUEIRÓS, Sônia. Na captura da voz as edições da narrativa oral no Brasil. Belo Horizonte: Autêntica, 2004

ALMEIDA, Maria Inês de. Desocidentada: experiência literária em terra indígena. Belo Horizonte: Editora UFMG, 2009a.

ALMEIDA, Maria Inês. O livro selvagem. Revista Polichinelo, Belém (PA): Palmas (TO), p. 60-62, abr. 2009b.
BARRA. C. C. S. Literaturas de autoria indígena e revitalização das línguas indígenas. In: BONFIM, Anari Braz; COSTA, Francisco Vanderlei Ferreira da. Revitalização de língua indígena e

educação escolar indígena inclusiva. Salvador: Empresa Gráfica da Bahia/EGBA, 2014. p. 57-80.

BICALHO, Charles. Koxuk, a imagem do Yãmîy na poética

Maxakali. 2010. 229 f. Tese (Doutorado) - Pós-Graduação em

Estudos Literários, Faculdade de Letras, Universidade Federal de Minas Gerais, 2010

BLANCHOT, Maurice. O espaço literário. Rio de Janeiro, Rocco 1987.

BLANCHOT, Maurice. O livro por vir. Lisboa, Relógio D’Água, 1984.

BORGES, Luiz Carlos. Os Guarani Mbyá e a oralidade discursiva do mito. In: FERNANDES,

Frederico Augusto Garcia (Org.). Oralidade e literatura manifestações e abordagens no Brasil. Londrina: Eduel, 2003. p: $1-20$.

FUNASA. O parto e o resguardo Maxakali. Cartilha. Projeto Vigisus II, SUS, [s.d.] 14 páginas.

KAXINAWÁ. Shenipabu Miyui: história dos antigos. Belo Horizonte: UFMG/OPIAC, 2008.

KAXINAWÁ. Shenipabu Miyui: história dos antigos. Rio Branco: Ed. OPIAC 1995. 
KEHÍRI, Tõrãmu; PÃRÕKUMU, Umusi. O mito de origem da noite.

In: Antes o mundo não existia: mitologia dos antigos

Desana-Kehíripõrã. 2. ed. São João Batista do Rio Tiquié: São

Gabriel da Cachoeira: UNIRT/FOIRN, 1995. (Narradores Indígenas

do Rio Negro, v. 1).

KUMU, Umúsin Panlõn; KENHÍRI, Tolamãn. A estória de Ñami

ou a origem da noite. In: Antes o mundo não existia:

mitologia heróica dos índios Desâna. Introdução de Berta Ribeiro.

São Paulo: Livraria Cultura. 1980. p. 81-87.

LANA, Feliciano Pimentel. A origem da noite e Como as

mulheres roubaram as flautas sagradas. Duas histórias

ilustradas e contadas em Desana. 2. ed. Manaus: EDUA. 2009

(Série Autores Indígenas).

MAXAKALI, Rafael et al. Hitupmã'ax: Curar. Belo Horizonte:

Faculdade de Letras da UFMG; Cipó Voador, 2008.

MEDEIROS, Sérgio L. R. Ainda não se pode ler em Xavante.

In: MEDEIROS, Sérgio; DINIZ, Alai Garcia (Org.). NELOOLL.

Florianópolis: NELOOL (UFSC), 2006, v. 1, p. 1-6.

RISÉRIO, Antônio. Textos e tribos: poéticas extraocidentais nos

trópicos. Rio de Janeiro: Imago, 1993.

VELOSO, Caetano. Noites do norte. Álbum discográfico.

Universal Music, 2000 